\title{
The liberation of nature and knowledge: a case study on Hans Reichenbach's naturalism
}

\author{
László Kocsis ${ }^{1}$ [D Adam Tamas Tuboly ${ }^{2,3}$ (iD
}

Received: 30 November 2020 / Accepted: 18 May 2021 / Published online: 27 May 2021

(c) The Author(s) 2021

\begin{abstract}
Our main goal in this paper is to present and scrutinize Reichenbach's own naturalism in our contemporary context, with special attention to competing versions of the concept. By exploring the idea of Reichenbach's naturalism, we will argue that he defended a liberating, therapeutic form of naturalism, meaning that he took scientific philosophy (or philosophy of nature, Naturphilosophie) to be a possible cure for bad old habits and traditional ways of philosophy. For Reichenbach, naturalistic scientific philosophy was a well-established form of liberation. We do not intend to suggest that Reichenbach acted as an inventor of naturalism; nonetheless, invoking the term and the idea of 'naturalism' is more than a simple rhetorical strategy for rehabilitating Reichenbach as a forerunner of this field. We think that his ideas can make a valuable contribution to contemporary debates, and that he presents an interesting case among the other scientifically oriented proponents of his time. After presenting a short reconstruction of the meaning of naturalism-or, more appropriately, naturalisms - in order to be able to correctly situate Reichenbach within his own as well as a systematic context, we discuss Reichenbach's naturalism against the background of his scientific philosophy, his views on the relation of commonsense knowledge to science, and his efforts at popularization. To delve deeper into this topic, we present a case study to show how Reichenbach argued that in both scientific and philosophical discussions (assuming their naturalistic continuity), it is necessary to move from the request and value of truth to probability. And, finally, we argue that the liberation of knowledge and nature was a socio-political program for Reichenbach, who talked about his own scientific philosophy as "a crusade." By emphasizing this aspect of Reichenbach's naturalism, we may be in a better position to situate him in the history of analytic philosophy in general, and in the yet-to-bewritten narrative of the naturalistic movement in particular.
\end{abstract}

Keywords Naturalism $\cdot$ Scientific philosophy $\cdot$ Common sense $\cdot$ Truth $\cdot$ Probability

This article belongs to the topical collection "All Things Reichenbach", edited by Erik Curiel and Flavia Padovani.

Extended author information available on the last page of the article 


\section{Introduction}

As the leader of the Berlin Circle of logical empiricism, Hans Reichenbach paid special attention to the practical and theoretical dimensions of the sciences. Within his own narrative of the meaning of logical empiricism, he repeatedly differentiated himself and his own circle from the one that emerged around Moritz Schlick and later became globally known as the Vienna Circle. In light of the many concrete differences, Reichenbach (1936, p. 144) formulated a general dissent as well: "In line with their more concrete working-program, which demanded analysis of specific problems in science, [members of the Berlin Group] avoided all theoretical maxims like those set up by the Viennese school and embarked upon detailed work in logistics, physics, biology, and psychology."

While the members of the Vienna Circle, at least according to Reichenbach, developed and defended general philosophical theses, the scientific philosophers in Berlin dived into the actual problems of scientific theories and provided detailed analyses of the basic scientific, or scientifically relevant, notions of philosophy. How did they do so without admitting any dogmatically specific philosophical doctrines? In Reichenbach's view, the Berlin Group had a special program based on a specific attitude:

What unites the members of this group is not the maintenance of a philosophical "system," but a community of working methods-an agreement to treat philosophical problems as scientific problems whose answers are capable of soliciting universal assent. Philosophical problems, in other words, do not differ in principle from problems of the positive sciences. The strength of this group lies in its common working program and not in a common doctrine-a program which distinguishes it from philosophical sects, and makes possible progress in research. (Reichenbach, 1936, p. 142)

What we face here quite explicitly is the admission of what became known in the history of twentieth century analytic philosophy as naturalism.

Our main goal in this paper is to present and scrutinize Reichenbach's own naturalism in our contemporary context, with special attention to competing versions of the concept. By exploring the idea of Reichenbach's naturalism, we will argue that he defended a liberating, therapeutic form of naturalism (Reichenbach, 1931a/1978, p. 354), meaning that he took scientific philosophy (or philosophy of nature, Naturphilosophie) to be a possible cure for bad old habits and traditional ways of philosophy. For Reichenbach, naturalistic scientific philosophy was a well-established form of liberation.

We do not intend to suggest that Reichenbach acted as an inventor of naturalism; nonetheless, invoking the term and the idea of 'naturalism' is more than a simple rhetorical strategy for rehabilitating Reichenbach as a forerunner of this field. We think that his ideas can make a valuable contribution to contemporary debates, and that he presents an interesting case among the other scientifically oriented proponents of his time. In Sect. 2, we thus present a short reconstruction of the meaning of naturalism — or, more appropriately, naturalisms - in order 
to be able to situate Reichenbach correctly within his own as well as a systematic context. Section 3 then discusses Reichenbach's naturalism against the background of his scientific philosophy, his views on the relation of common-sense knowledge to science, and his efforts at popularization.

To delve deeper into this topic, in Sect. 4 we present a case study to show how Reichenbach argued that, in both scientific and philosophical discussions (assuming their naturalistic continuity), it is necessary to move from the request and value of truth to probability. While the probabilistic feature of Reichenbach's general philosophy is often acknowledged in the literature, how he arrived at accepting this approach by way of naturalistic reasoning is less discussed, or even noted. Finally, in Sect. 5, to provide a framework for our narrative, we return to Reichenbach's naturalism to highlight one of its major and rarely mentioned aspects, namely its socially engaged character. The liberation of knowledge and nature was a socio-political program for Reichenbach, who talked about his own scientific philosophy as "a crusade." By emphasizing this aspect of Reichenbach's naturalism, we may be in a better position to see him in the history of analytic philosophy in general, and in the yet-to-be-written narrative of the naturalistic movement in particular.

\section{A Tapestry of naturalisms}

Naturalism is perhaps one of the broadest umbrella terms in philosophy. As Kelly James Clark (2016, p. 1) notes, naturalism "admits of no single, simple definition and comes in a wide variety of shapes and sizes [...]. Defined too narrowly, it leaves out wide swaths of human thought and experience; defined too broadly, it includes many things that naturalists hope to exclude." Although one might reasonably expect to find at least some basic shared assumptions and commitments among those who self-identify as naturalists, a term as vague and general as "naturalism" has little promise of philosophical significance. Nonetheless, "at the turn of the twenty-first century, naturalism is the reigning orthodoxy assumption of most faculty in most universities across the English-speaking world" (ibid.), meaning one has no choice but to walk the naturalist path in order to draw a more nuanced map of the possible commitments and engagements.

Typically, two basic forms of naturalism can be distinguished. The first is metaphysical naturalism, an ontological standpoint that claims that only natural entities (whatever they might be) exist while supernatural ones do not. As such, metaphysical naturalists often reject the existence of God, angels, souls, ghosts, and similar spooky entities whose admittance to the natural furniture of the world would seem impossible. But even someone who believes only in natural entities might conduct philosophical research by relying on a priori or intuitive means. This brings us to a second form of naturalism, namely methodological naturalism. Its adherents think that science provides the most reliable and useful path to knowledge, whose basic empirical and intersubjective method should thus be followed even inside philosophy. In their scientific work, even scientists who otherwise believe in supernatural entities should follow the path of empirical research wherever it may lead them. In that sense, methodological naturalism may be compatible with a variety of 
ontological packages, especially if one admits that ontology has nothing to do with science.

In the literature, especially after the work of Quine, one often encounters the idea of what might be termed metaphilosophical naturalism. This amounts to the idea that there is no external philosophical perspective from which one could explore the truth about the world independently of the sciences in any a priori ways. As a consequence, philosophy is unable to establish the sciences, or to act as a solid foundation on which they could build (for example, in the manner of certain interpretations that claim that Kant sought to establish the Newtonian results from a critical-philosophical point of view). While this continuity idea is one of the most often noted characteristics of naturalism, it is debatable whether we should distinguish it from methodological naturalism. In this paper, we do not make such a sharp separation, and will also refer to the metaphilosophical idea for the sake of simplicity, and will note only that-mainly due to Quine - the 'no prior philosophy to science' became standard for many naturalists within and outside of Anglophone philosophy. ${ }^{1}$

In the mid-twentieth century, Quine was neither the first nor the only naturalist. While his nod towards John Dewey was quite symbolic (Verhaegh, 2018, p. 158), in the United States, naturalism was connected to Dewey and the scholars around him at Columbia University. An edited volume from 1944 contains the following manifesto, which can be read as a self-characterization:

[Naturalism] carries on the idealistic emphasis that man is united to his world by a logical and social experience. But it rephrases the idealistic scheme of man's activities and environment in biological and anthropological categories. While like the idealists it makes them all amenable to a single intellectual method, it reformulates that method in experimental terms. (Randall, 1944, p. 373)

This is a very basic and broad statement; it points toward a highly integrated and complex picture of nature where both logic (human reason and intellect) and emotions (feelings, customs, traditions, conventions) have a role to play, given that they are studied by the same empirical and experimental method of the natural sciences. This view, defended in various forms and ways by Roy Wood Sellars, John Dewey, Frederick J.E. Woodbridge, Morris Raphael Cohen, John Herman Randall, Jr., and Ernest Nagel, often goes by the name "Columbia naturalism" (Jewett, 2011).

It is not a reductivist position: it does not try to reduce the complexity and context-sensitive character of human life and values to some basic mechanical-atomistic-physicalist-or-whatever basis of the natural sciences. In another programmatic paper, Ernest Nagel (who served for a long time as a bridge between European logical empiricism and American pragmatist naturalism) claimed that naturalism, as understood at Columbia, is "vigorously anti-reductionist" (1947/1954, p. 55) in the sense that "the world contains at least as many qualitatively distinct features as are

\footnotetext{
1 There are, however, principled differentiations between metaphysical, methodological, and even metaphilosophical naturalisms, especially in the context of experimental philosophy. See Fischer and Collins (2015, p. 26 ff.).
} 
disclosed in human experience," and thus the view that "the human scene is "nothing but' an aggregation of certain allegedly 'ultimate' elements" is false (ibid.).

For Nagel and for many others, naturalism did not proclaim any concrete values (although a strong preference for democratic ideals is more than evident in naturalist writings); as a meta-conception of inquiry, it explicitly admitted the significance of values and acknowledged their plurality in the world of social practices. Naturalism was not an abstract system that could be formalized by any means to strictly deduce further orders and necessary guidance; it was rather a worldview, an attitude that also had social relevance:

[C]ontextualistic naturalists confidently anticipate an increased moral enlightenment. [...] It is sane and reasonable at a time when the tides of irrationalism run high in the world and when substitutes for the Appolonian [sic] virtues are at a premium. It expresses the convictions of people confident that a bold but disciplined intelligence is still a creative power in the world. (Nagel, 1947/1954, p. 57)

Naturalism was thus also a moral and political approach; by acknowledging the socially anchored character of thinking and acting, naturalism argued that scienceand thus philosophy-is also socially relevant. In fact, as the naturalists rejected any strict and artificial separation between thinking and acting (which goes back to C.S. Peirce and later functioned as a measuring rod of the naturalists' own pragmatism and naturalism), all theoretical formulations (of philosophers, social scientists, natural scientists or representatives of the humanities) inevitably also had a sociopractical character. Columbia naturalism and Nagel's own contextualistic naturalism are evidently socially engaged meta-forms of philosophy, at least in the minimal sense that they acknowledge human values and needs in the process of philosophical thinking, and try to connect philosophical argumentation to the actual practice and structure of the world, by emphasizing the factors that inhibit system-building and formalism. $^{2}$

Naturalism had many faces, and it continues to be discussed for good reason. While most naturalists agree with the idea that whatever the method of science, it must be followed and cannot be superseded or overwritten by philosophy, it is important to note two things. First, there is the question of what happens when science requires methods that are disdained or rejected by naturalists, such as intuition, guessing, and a priori theorizing. As we shall see below, Reichenbach thought that

\footnotetext{
${ }^{2}$ It is no big surprise, then, that many New York intellectuals welcomed Neurath and his allies warmly in the United States during the mid-1930s (Reisch, 2005). It has to be noted, however, that Nagel was often very critical of Reichenbach. Besides arguing against the latter's account of probability, Nagel claimed that Reichenbach's Experience and Prediction presents a duplication of reality (what seems to be a case, and what is in fact the case), confirming the traditional form of philosophy whose epistemological problems were "buried long ago by American pragmatists" (Nagel, 1938, p. 272). Nagel's view also amounts to a specific form of naturalism, which we cannot consider here in detail-our aim is merely to note that it may be possible to construe a narrative in which Reichenbach's and Nagel's socially functioning naturalisms differ only in their specific details whereas their main programs converge. On Nagel's naturalism, see the essays in Neuber and Tuboly (2021).
} 
many of these methods (of discovery) could be "naturalized" and thus annexed even by a hardcore naturalist. ${ }^{3}$ Secondly, one might ask what science we are talking about in the first place. The various natural, social and human sciences are presumably (or at best) connected by family resemblance-and by emphasizing one of them, one may arrive at a different form of naturalism, and that specific form might then annex different fields of life for the naturalist. Take Quine, for instance: he is known for bringing psychology to the forefront of naturalism and based his own "naturalized epistemology" on psychological and especially behaviorist considerations. But we rarely find any passages in Quine supporting the notion that the momentous revolution of physics in the twentieth century would dictate that our knowledge-production machinery and concepts should also follow the path of physics. And there is almost nothing in his works about how history might be utilized in concept formation and how ethical issues are embedded in the social world. As a result, Quine's naturalism might be conceived of as psycho-behaviorist naturalism.

Thomas Uebel (2007) has emphasized in great detail that Neurath's own philosophical practice (and metatheory) was an early and broad form of naturalism thatsimilarly to Quine's_-did not rely exclusively on physics, but—unlike Quine'scombined the natural sciences with a substantive amount of the social sciences. While the natural sciences gave our view of science its backbone, sociology and history provided its flesh and blood (in Neurath's case, with a non-negligible grain of economics, of course). Consequently, Neurath's socio-historical naturalism was not just an early predecessor to Quine's naturalism, but an important alternative as well.

But besides the social and the physical sciences, many naturalists also utilized biology in their programs. Herbert Spencer's Darwinism, or Dewey's (1910) early middle phase may come to mind, but neurobiology also played an important role in the second half of the twentieth century (Dretske, 1995). These authors often focus

\footnotetext{
${ }^{3}$ One of our referees raised the question of how to account for Reichenbach's famous distinction between the contexts of discovery and justification, often seen as a fundamentally anti-naturalist gesture (demarcating epistemology from psychology). While it might be true that philosophy of science is concerned with rationally sanitized scientific products rather than with psycho-socially embedded vague considerations, the tension between discovery and justification could be resolved by means of the continuity of metaphysical, methodological, and metaphilosophical theses of naturalism. After all, for naturalists, psychology is just one issue among many, and Reichenbach indeed incorporated many biological and evolutionary issues into his epistemology. However, as we also stated above, Reichenbach's own approach, viewed under the "naturalist" or the "scientific philosophy" banner, could lead to significant tensions. Don Howard (2006) points out, for example, that Neurathian naturalism, embracing different values in theory choice, was the target of Reichenbach's original distinction, and that recent naturalistic philosophy of science has gone in the direction of Neurath (and Dewey) rather than of Reichenbach. (This view is somewhat contradicted, or at least extended, by Alan Richardson (2006, p. 42) who claims that since philosophy of science is concerned with the construction of the context of justification, "Reichenbach's account of epistemology gives scientific philosophy a social function and, ultimately, a political significance". We are not claiming, of course, that what we call "the social function for Reichenbach" below coincides with Richardson's interpretation and intentions, but at the very least it shows the richness of Reichenbach's thought when it comes to similar interpretations and projections.) Be that as it may, the context distinction could be viewed from many (non-canonical) angles (even perhaps, for example, as a naturalist attempt to scientifically account for seemingly irrational or subjective moves in the scientific enterprise), and Reichenbach may thus be reprimanded for his seemingly too dry version of naturalism (though it still seems to exhibit greater vividness than Quine's).
} 
on the capacities and abilities of the mind and how human thinking is determined by biological factors. In their brand of naturalism, the final explanatory tool was often a certain form and degree of evolution, which is why these biological naturalists refer less and less to the overwhelming achievements of physics or the contextualizing character of the social sciences.

Bringing to light all these different versions of naturalism points toward further investigations into the history of the concept and its systematic possibilities. But it is important to note one thing in particular: naturalism, for most of the abovementioned figures, was not just a theoretical doctrine about ontology or the scientific method. Naturalism was a worldview, supported and launched by the overwhelming success of the sciences in the nineteenth and twentieth centuries. And as such, naturalism also included a broader, socio-ethical aspect and commitment. While Quine, the analytic philosopher par excellence, might not fit this broader characterization of naturalism entirely, we indeed think that Reichenbach represents a missed opportunity in the history of analytic philosophy for exemplifying naturalism on a grand scale.

\section{3 "If Science has spoken, common sense has to keep quiet": on Reichenbach's naturalism}

None of Reichenbach's writings contains the word 'naturalism' as a self-conscious label for his own position. This is obvious given that naturalism, as we usually understand it, became fashionable in the United States, and it was often associated, above all, with pragmatist philosophers. While he was in Europe and Turkey, Reichenbach used the term 'physicalist,' though presumably not exactly in the sense of Otto Neurath, and surely not with the intention of following him in any way.

Reichenbach was called something like a 'naturalist' quite early on. After Sidney Hook returned to the United States from his general tour of Europe to consider and study European, especially German, philosophy in 1929, he published a long article about the socio-cultural and intellectual landscape as he experienced it. Besides his rather negative evaluation of contemporary German philosophy, Hook (1930, pp. 159-160) emphasized Reichenbach's philosophy, which is “associated with men like Schlick, Carnap, and Grelling, although his position is more naturalistic than theirs. [...] A naturalistic interpretation of the a priori is defended in his polemic against Kant [...]."4 In other words, Reichenbach was seen by one of the leading American pragmatists as a useful ally for American naturalists.

The story of how Reichenbach arrived in the United States through Turkey in the late 1930s is a long one (Verhaegh, 2020 fills in many gaps, also providing

\footnotetext{
4 It's a matter of discussion whether Reichenbach's interpretation of the a priori was indeed more naturalistic than Carnap's at the time. We do not have any information on what Hook gleaned from Carnap, but presumably he did not go into the details of the Aufbau and Carnap's other available writings from the 1920s exhibit a conventionalism seemingly inspired by Poincaré-Dingler, rather than a biologically and physically influenced naturalism (although it should also be noted that the interpretation of Carnap's writings from the 1920 s is still contested). We thank one of our referees for raising this point.
} 
information on how Reichenbach moved from his original German context and literature to his new Anglophone one). This journey also involved an intense intellectual apprenticeship for Reichenbach to become acquainted with American philosophyand with the publication of Experience and Prediction (1938) and a longer contribution to Dewey's 'Library of Living Philosophy' volume, he was on track. In the latter piece, Reichenbach distinguishes philosophies that exemplify "negative attitudes" from those that display "affirmative attitudes" toward our world (this quasi-moral differentiation became canonical in his work; see the last section of this paper). To the first group belong thinkers who deem the world we live in to be unsatisfactory, insufficient, and imperfect and who thus posit another realm that also includes transcendent beings and values. For the affirmative or positive-attitude philosophers, "life [...] bears its value in itself and does not derive it from supernatural entities [and] knowledge for them is directed towards this world, and all transcendent interpretations appear to these philosophers as turning away from the sound basis of our existence, as flight from this world" (Reichenbach, 1939, p. 159). To make this point more explicit, Reichenbach refers to these two groups as "other-world philosophies" and "this-world philosophies."

While Reichenbach's paper is a critical appraisal of Dewey, who obviously belongs to the category of "this-world philosophers," Reichenbach (1939, p. 160) states that "he considers himself a member of the same group." By laying his cards on the table, Reichenbach makes explicit his commitment to metaphysical natural$i s m$, that is, to the denial of supernatural entities. He makes great efforts to argue for a certain form of realism to include unobservable and theoretical entities in the naturalist picture of the world, ${ }^{5}$ and he does not accept any ontological categories that point beyond the empirically and intersubjectively confirmed realm of the natural sciences.

But how is Reichenbach's naturalism structured further? In his programmatic article, "Aims and Methods of Modern Philosophy of Nature," he maintains that there would be no chance to solve certain philosophical and especially epistemological problems if the philosophy of nature were separated from the philosophy of the natural sciences. Though, according to Reichenbach, the philosophy of nature is inseparable from the philosophy of special sciences, they are not identical. The difference between them is not sharp: when we do philosophy of nature, we are sometimes interested in more comprehensive problems than those addressed by the philosophy of special sciences. Reichenbach definitely maintained the primacy of special sciences, convinced that "there is a gradual transition from the problems of the special sciences to these more comprehensive problems" (1931b/1978, p. 381). This makes him a metaphilosophical naturalist who reserves no place for philosophy to provide foundations for the sciences. Whatever the exact nature and role of philosophy might be- " $[\mathrm{t}]$ he only form of philosophy that must be rejected is that which attempts to

\footnotetext{
5 Reichenbach's realism about unobservable entities is based partly on his arguments for a probabilitybased scientific epistemology, in which he replaced the absolute concept of truth with the concept of probability; Sect. 4 of this paper will discuss Reichenbach's main reasons for this replacement. Psillos (2011) discusses Reichenbach's sophisticated scientific realism in detail. See also Putnam (2001).
} 
prescribe for the physicists the results or methods of his science"-it is strictly and strongly connected to the sciences (Reichenbach, 1929/1978, p. 123). ${ }^{6}$

Reichenbach reserves a significant place for traditional epistemology, though in modernist clothing, under the name of 'scientific epistemology':

When I speak of epistemology, I have in mind something different from large circles of contemporary academic philosophers. That is, I do not understand by the term a discipline that produces knowledge from pure reason and then lays down prescriptions for scientists in the various specialties. Rather, I see epistemology as being inextricably bound up with the exact sciences. For the methods of epistemology can only consist in the analysis of scientific thinking; the sciences must be analysed with the help of logically axiomatic methods if questions regarding the meaning and presuppositions of knowledge are to be answered. The turning from an analysis of the knowing mind to an analysis of the crystallised product of knowledge is the characteristic feature of modern philosophy of science. (Reichenbach, 1931a/1978, p. 343)

By 'exact sciences' he essentially meant the natural or physical sciences. Reichenbach was a trained physicist, one of the few attendees of Einstein's early seminars on general relativity in Berlin. His major early publications are all connected to axiomatizations in physics, the philosophical interpretations of physics, and the epistemological implications of the physical sciences. ${ }^{7}$ Whenever he needed an example

\footnotetext{
${ }^{6}$ For Reichenbach, the continuity between science and philosophy was bidirectional. While philosophy should learn and start from the sciences, there is still some individual role for it to play: "But a philosophy that draws its facts from science, that is able to shed light upon the mysteries of scientific research and clarify for the investigator by means of his own accomplishments the ends and the methods of his work, can only serve as a welcome ally along the path to knowledge" (1929/1978, p. 123). One cannot but wonder what Reichenbach would have thought of the descriptivist approaches of later sociologists of science who sought to shed light on these mysteries, to clarify the aims, means, and contexts of research, and to investigate the actual methods of science. On the other hand, there is another possible tension in Reichenbach's naturalistic approach that needs to be emphasized. Already in his 1947 Elements of Symbolic Logic, but explicitly in his Laws, Modalities, and Counterfactuals (1976, published originally in 1954 as Nomological Statements and Admissible Operations), Reichenbach was engaged in Carnapian explication, "constructing a precise term proposed to take over the functions of a vague term" (1976, p. 2). In general, Carnapian explication and rational reconstruction (notwithstanding the differences between the two) are taken to be anti-naturalist programs par excellence (especially in contrasts to Quine's descriptivist naturalism). Nonetheless, a back door to the explicatory edifice could be opened up for naturalism (see the essays in Wagner 2012), thereby reserving a place for Reichenbach as well. Note also that Reichenbach's Elements of Symbolic Logic_-and the "logistic grammar" it employs for the logical analysis of conversational language - is still underrated and has not yet been discussed in the literature. The only major exception is McMahon (1976), though he, in fact, shows that Reichenbach anticipated many of Chomsky's key points and achievements, which again opens up an important domain for a naturalist interpretation of Reichenbach, especially against the background of the Quine-Chomsky debate.

7 In the above-cited paragraph, Reichenbach emphasizes the importance of "the help of logically axiomatic methods" in the analysis of scientific theories. One of our anonymous referees highlighted that this point might generate some tension in our naturalistic interpretation of Reichenbach, since it is not clear how Reichenbach can be seen as a naturalist if he is committed, similarly to Carnap, to the analytic/synthetic distinction of a priori axioms of coordination from the empirical axioms of connection. On the other hand, especially in the light of the Quinean critique, what is a naturalist to do with this Reichenbachian distinction between the two kinds of axioms? No doubt, according to Quine's criticism,
} 
to substantiate a point, to draw a scientific parallel to epistemology, or to mark the characteristics of philosophy in relation to science, he always turned to physics (for further examples and a case study, see Sect. 4 below).

For these reasons, Reichenbach did not consider in any detail the implications of biology or psychology for scientific and human understanding: his philosophical naturalism was based on the results of the physical sciences (though, as we shall see in a moment, he incorporated a general evolutionary-physiological lesson into his view of humanity's place in the world). Thus, in the final sentence of "The Physical Concept of Truth," he offers the following diagnosis of the close connection between the non-academic, scientific epistemology he propagated and the evolution of contemporary physics: "[t]he intermingling of physical problems with epistemological problems is greater today than ever before-to the benefit, I believe I may say, of both" (Reichenbach, 1931a/1978, p. 355).

As we have thus seen, Reichenbach was both a metaphysical and a metaphilosophical naturalist, but he could also be considered a methodological naturalist, since he tried to secure the methods of science in philosophy by pursuing the strictest lines of "scientific philosophy." However, as we noted in the context of the Columbia naturalists, naturalism is a broader concern than just a methodological framework for philosophy. Natural scientists and naturalists often face opposition because their worldview supposedly tries to undermine and reduce the significance of all those elements in life that are not subsumable under the umbrella of actual science. Reichenbach was aware of this possible charge and went to great lengths to answer the broader questions of life in accessible forms. Besides his regular popular articles in newspapers (collected in Part II of Reichenbach 1978), he broadcasted several radio lectures in 1929. Reichenbach was a gifted speaker who knew how to engage his listeners and how to turn complex and abstract material into understandable and approachable discourses, as proven by the printed versions of his radio

\footnotetext{
Footnote 7 (continued)

introducing the distinction between analytic and synthetic statements prevents the acceptance of the naturalist thesis about the continuity of philosophy and the natural sciences. We only have two very short remarks in this regard. First, it is not clear whether a naturalistic (meta)philosophy can only be elucidated and accepted if one agrees with a radical Quinean attack against the analytic-synthetic distinction. In Sect. 2, we discuss naturalistic tendencies before Quine and these naturalisms are, of course, not Quinean. Moreover, we do not claim that Reichenbach was a naturalist in a Quinean sense; what we assert is that Reichenbach's philosophy of nature can be interpreted as a form of naturalism. Secondly, Reichenbach's distinction between the a priori axioms of coordination and the empirical axioms of connection does not correspond neatly to the version of the analytic/synthetic distinction that Quine attacked in his "Two Dogmas". As is well known, axioms of coordination are a priori not in a Kantian apodictic sense, but in a constitutive sense, and as such they are synthetic, framework-relative and, according to the orthodox view, not as certain as analytic statements. Though this question cannot be answered in detail here, we are confident that Reichenbach's distinction between the a priori and empirical axioms of a scientific theory can be reconciled with the naturalistic attitude of his scientific philosophy. For more on Reichenbach's axiomatic method, in particular the axioms of coordination and their role in his scientific philosophy, see Padovani $(2011,2021)$.
} 
lectures, Atom und Kosmos, published in 1930 (an English translation followed two years later). ${ }^{8}$

But why did Reichenbach feel the need to engage the public as a naturalist? With all the expected and unexpected changes in the development of the sciences after the mid-nineteenth and especially during the early years of the twentieth century, the rupture between the views of the world presented by the sciences and those of laypeople increasingly deepened. In the latter's world, objects can be seen and touched, they are hard or soft, and have a certain color-in Reichenbach's words, they follow "certain simple and reliable laws of behavior." As he puts it, "[t]his picture of the world has a simple cosmology, too; there is a sky over us, across which the constellations take their way, and the whole universe is imbedded in space and time, whose basic properties are, as a matter of course, familiar to us" (Reichenbach, 1932b/1957, pp. 21-22). All human beings know this world from direct experience; it is the world of common sense, where the sun comes up and crosses the sky above our heads. But what about the world of science?

Here the uniformly filled substance of the naïve picture exists no longer; instead, there is really nothing but tiny granules, which whirl past each other in violent motion. The quiet, clear water in the lake, as the scientist conceives it, corresponds rather to a swarm of gnats, all swirling to and fro; there is no surface, but only a vague frontier zone, from which water particles are ever shooting into the air, while others come through this zone from the atmosphere. Even the bridge pier of iron, which rises from the water and seems a symbol of repose and sustaining strength, reveals itself to the closer observer as a quivering structure, whose particles tremble in confusion, like the fine ramifications of a panicle of elderberries [...]. When a railway train passes over the bridge, we must not think that the wheels touch the rails, but merely that the surfaces of two such systems of quivering clusters come close enough for the repulsive forces to keep the particles away from each other. And in this world of shaking clusters and swarms of gnats there is not light, no colour, no sound; those, in turn are but tremblings of another kind [...]. (Reichenbach, 1932b/1957, p. 22) ${ }^{9}$

If the scientific image of the world differs at every basic point and to such a degree from the common-sense picture of the world, then the acceptance and propagation

\footnotetext{
8 In fact, Atom and Cosmos was not the first of Reichenbach's popularizing books; in 1927, he published a short booklet called From Copernicus to Einstein (first in German, followed by the English translation in 1942).

9 In light of these passages, it is very tempting to compare Reichenbach's popularizing works to those of Arthur Eddington and James Jeans who published their own philosophical texts in 1928 and 1930, respectively. Eddington (1928, pp. ix-xi) famously compared his two tables, namely the table of common sense (colored, substantial, has extension) and his scientific table (non-substantial, does not have any of the usual qualities). One could therefore read Reichenbach's book as a response to Eddington and Jeans, who were famously led to a very radical idealism by their considerations of the new physics of relativity and quantum mechanics.
} 
of naturalism (and thus the worldview of science) indeed requires some efforts of explanation. Reichenbach had an answer ready at hand.

In his view, one of the possible ways of communicating that naturalism is a viable worldview is to be found in the complex relation of common sense to scientific knowledge. Philosophers often rely on commonsensical conceptions of knowledge, values, and the world around us. These common-sense ideals are supposedly rooted in specific intuitions, or in the simple usage of our faculty of reason. In fact, they are worse than that:

What the philosophers of the naive world view present to us as theory of knowledge is nothing but the analysis of those scientific findings which have already been assimilated by the educated person of our time. What such a common sense theory of knowledge supplies is, therefore, nothing but the scientific conception of a few hundred years ago. Thus Galileo and Copernicus are acknowledged, Einstein and Heisenberg are rejected. Under these conditions, we should prefer an epistemology which consciously takes its starting point from the natural science of the present and whose philosophic results compare qualitatively with the scientific results of our contemporaries. (Reichenbach, 1931b/1978, p. 361)

To summarize this thought, common-sense knowledge is reactive and often does not follow the latest development of science. Common sense is thus an older system of science that scientists have already left behind or are in the process of subjecting to close and critical scrutiny. ${ }^{10}$

But this process of domestication, so to speak, of actual scientific practice and results concerns everyone involved. Talking about his seminars on relativity in an interview, Reichenbach said that

[a]t that time I had to give up as untenable a whole series of views that had previously appeared to me to be unshakeable truths. That was about sixteen years ago: in the meantime I have been able to give this new image of the universe a philosophical interpretation and have subsequently become so at home in it that I now find it difficult to visualize the older conception of space and time at all. (Reichenbach, 1932a/1978, p. 277)

Science aims at shaking our deepest and most solid convictions; but the reason that it is even capable of doing that, beyond merely aiming to do so, is that most of those convictions are, to use Philipp Frank's word (1941/1949), "petrifications" of older scientific considerations.

The defenders and users of common sense are, of course, not necessarily aware of this. Rather, they rely on intuitive and self-evident methods and ideas in their reasoning, often emphasizing the 'naturalness,' 'obviousness,' and 'self-justifying' character of everyday knowledge. But Reichenbach (1951, p. 141) criticizes such

\footnotetext{
10 A few years later, Philipp Frank (1941/1949) also claimed that comprehensive philosophical systems are nothing but petrifications of former scientific theories contradicted by the advancement of science. For further elaboration of this idea in Frank, see Tuboly (2021).
} 
"self-evidence" as a guide to philosophical insights, arguing that "what [the philosopher] regarded as laws of reason [in the context of geometry] was actually a conditioning of human imagination by the physical structure of the environment in which human beings live". ${ }^{11}$ In his contribution to The Philosophy of John Dewey, he summarizes this idea as follows:

[T]he scientist shows that colours in general are products of human sense organs. He shows at the same time that even the eye of the normal man has only a very limited range of sensitivity, that we are all colour-blind, even blind, relative to electric waves outside a small range of wave lengths. [...] [I]f our eyes were sensitive to ultraviolet or infra-red rays, the world would be richer in colours and look different from what it looks now; if they were sensitive to cosmic rays, the sky at night would be bright with a maximum zone of brightness near the galaxy, etc. (Reichenbach, 1939, p. 178)

Consequently, what seems to be an intuitive, self-evident method or idea is just a conditioned behavior; as such, common sense is either rooted in certain existential conditions (e.g. in our physiological and evolutionary capabilities), or, where it is seemingly related to theoretical reasons, then those reasons also turn out to be (socio-historically) conditioned.

Reichenbach utilized this form of criticism quite early on (and thus it is not surprising that Hook recognized Reichenbach's naturalism). In The Theory of Relativity and A Priori Knowledge (1920/1965), Reichenbach disassembles Kant's notion of a priori into its two elements, namely the necessary/universal and the constitutive a priori. While he accepts the latter (i.e., that there are elements of our cognition that contribute to our knowledge independently of experience), he rejects the universality and necessity of Kant's categories:

The logical analysis of the judgments from which the table of the categories is derived did not result from immediate contact with the cognitive process, but represents a speculative order-schema of reason adopted for the cognitive process in virtue of its self-evidence. Essentially, the system of his a priori principles represents merely a sanctification [Heiligsprechung] of 'common sense' [...]. (Reichenbach, 1920/1965, p. 73, translation slightly modified)

Recourse to the unquestioned, general, and unified concept of a priori means losing the chance to see more clearly the epistemic status of scientific statements and common-sense considerations. Taking a priori at face value is dangerous, since " $[\mathrm{t}]$ oo much that was described by earlier philosophers as priori has fallen by the wayside

\footnotetext{
11 When Reichenbach was asked in a 1932 interview whether he would offer biological reasons to explain why people fail to understand the closedness and finiteness of space, he claimed that "[p]erhaps, although in this particular instance it is quite possible to bring about intuitive visualization through training. Modern geometricians have learned to visualize intuitively spaces having a non-Euclidean structure. It is really just a matter of excluding certain covert presuppositions that we all carry along with us from daily experience and which restrict our mind without our noticing it at first. Certainly, it requires a lot of training and serious concentration to discern these connections; more than anything, it takes good faith to really grasp the new forms of thought" (Reichenbach, 1932a/1978, p. 277).
} 
as science progresses" (Reichenbach, 1932a/1978, p. 278). The right conclusion, according to Reichenbach, is not that science violates our most basic and essential assumptions and has thus taken the wrong path, but to recognize that these assumptions have a special socio-historical relation to the world.

In fact, Reichenbach distinguishes between different forms of conditioning and determinateness. He claims that we are biologically or physiologically determined to experience the world in a particular way, while admitting variances in degree and form. He calls the qualities revealed by our senses secondary qualities or "biological constants, i.e., determined by the biological structure of the human body and therefore not susceptible to change" (Reichenbach, 1939, p. 180)—or at least they are not subject to constant and major changes within one's lifetime; while Reichenbach does not say so explicitly, the experience of this consistency and constancy would also explain the necessity attributed to these factors in explanations of the world. Milič Čapek (1957, p. 47) —author of one of the few systematic studies of Reichenbach's metaphilosophy and epistemology—calls Reichenbach's view "the biological theory of knowledge" (original emphasis) and explains Reichenbach view of our physical knowledge as follows: "the classical-that is, Newton-Euclidian-form of the human intellect is a system of intellectual habits acquired in a process of evolutionary adjustment to a limited segment of reality" (ibid., p. 49, original emphases).

Reichenbach (1939, p. 181) talks about "tertiary qualities" of both ethics and aesthetics, but he thinks that these "depend on the social milieu of the observer and are amenable to change by education and new social adjustment". This social determinateness is more flexible and open to constant change. As people change their social position and move within the cultural web, the various influences on their thinking are constantly changing. At first glance, Reichenbach agrees with all naturalists and pragmatists in keeping the socio-ethical issues under guidance of social conventions by at least noting (if not developing in detail) the outlines of a naturalist ethical theory. However, in contrast to Dewey, for example, Reichenbach does not think that the ethical and social fields are as objective as the physical. Regarding emotional qualities, he notes that "a black cat may appear frightful to one man, whereas another sees it as a graceful and tender animal. This is why we call these qualities subjective" (Reichenbach, 1939, p. 177). He claims that the very same physical stimuli or objects produce very different emotions (and attitudes), varying from person to person, which makes emotional qualities rather subjective and flexible. Reichenbach thus does not share the inclination of the pragmatists, and presumably of many naturalists, to establish an objective socio-ethical theory in which their judgments would constitute facts of the matter.

If the term " objective esthetics and ethics' is to have any meaning for a theory of action," he argues,

it must mean that esthetical and ethical properties can be demonstrated to every man as properties of things, i.e., that they are intersubjective properties. But we know that this is not possible. [...] [T]he pragmatist's 'reality' of secondary and tertiary qualities cannot furnish the very feature which would justify a characterization of esthetics and ethics as objective: it cannot furnish a compulsory character of esthetic and ethical judgments. We are afraid that the 
pragmatist conception may lead for this reason to dangerous misunderstandings of value-judgments in so far as it may suggest a theory of ethics which considers moral judgments as binding as physical judgments. (Reichenbach, 1939, p. 178, p. 180, original emphases)

As socio-ethical qualities do not exist in the world on their own, they are subjective in the sense that they always involve the judging subject-in Reichenbach's (1939, p. 181) words, "moral judgments vary with the structure of the individual, and [...] as this structure is highly determined by the social environment, moral judgments vary with the social structure of society". Given that the world affects us-and thus shapes our intuitions, values, and opinions-people are able to shape the world as well. Volition, will, and similar subjective notions therefore quite explicitly came into the picture of Reichenbach's practical and even theoretical philosophizing (Kamlah, 2013). ${ }^{12}$ The epistemic agent who does scientific philosophy and acts in the social world plays a crucial role in Reichenbach's thinking - and as we shall see below (Sect. 5), he always admitted the social function of scientific philosophy in some way or other.

Be that as it may, Reichenbach further elaborates on the relation of common sense and scientific thinking:

[o]f course, we can speak of the common sense method of solving problems, but this method, once stripped of its emotional components and analyzed solely with regard to its cognitive content, does not differ in principle from the method of natural science. The difference is one of degree, and the fundamental concepts that are used, such as the concept of existence or the concept of truth, are the same in both. This fact is not always clearly apparent because the epistemological structure of the complex theories of science is not as primitive as that of common sense knowledge. (Reichenbach, 1931b/1978, p. 360)

The main difference between the common-sense method and that of natural science is that the latter is deeper, purer, more fine-grained, and more complicated. Before the logical empiricist turning point, the biggest mistake that philosophers of nature could (and actually did) make was to propose "that there exists a fundamental difference between the conception of knowledge in science and that in daily life, and that the proper starting point for epistemology is the common sense conception of knowledge" (Reichenbach, 1931b/1978, pp. 359-360).

In Reichenbach's view, the earlier philosophical attempts to discover the nature of scientific knowledge went astray because they stipulated the autonomy and primacy of philosophical presuppositions and their absolute validity for scientific ways of

\footnotetext{
12 Alan Richardson (2000, 2005) has put much emphasis on Reichenbach's volitional ideas (which presumably go back to his student days in the German Youth Movement—see Kamlah 2013), and thus interprets his ideas mainly within the boundaries of his thinking; Howard and Richardson offer a comprehensive and novel narrative of the willing social subject in Reichenbach's philosophy, but it would go beyond the scope of this paper to consider their ideas in more detail. On Reichenbach's so-called noncognitivism, see Damböck (2021).
} 
thinking. ${ }^{13}$ The older philosophies of scientific knowledge always sought to forego and govern the development of scientific research by unearthing the general source of the underlying principles of natural science. However, the modern history of science has shown that a strictly prescriptive, basically Kantian conception of scientific knowledge cannot anticipate the emergence of scientific problems; such a speculative, purely philosophical analysis of fundamental, epistemological concepts based on reason proved unable to answer the challenges of modern physics. The only option, as suggested by Reichenbach, is to investigate the scientific problems in their own right, without any philosophical preconceptions:

Academic philosophy reveals a complete misconception of the total situation by still clinging to the idea of the autonomy of philosophy. A philosophy which, independently of scientific research, engages in formulating laws for all fields of knowledge will eventually come into conflict with science. Today it is rather the autonomy of problems that must be recognized as basic in science and epistemology. (Reichenbach, 1931b/1978, p. 362, original emphases)

This gradual view of the relation of 'common sense' or 'everyday life' to the 'scientific view' also emerged from the following considerations. Reichenbach notes that in our everyday life, when confronted with the illusion of a stick "bending" under water, we tend to respond by saying that the stick is straight in fact, so that we are effectively "replacing the seen [bent] stick by another stick seeable in principle although not seen under present conditions." Thus, according to Reichenbach,

there are cases in which primitive experience compels us to abandon the perceived objects and to replace them be inferred objects the reality of which is better founded than that of the perceived objects. Why then not admit the possibility of similar corrections by the methods of science? These methods do not differ in principle from the correcting methods in the examples quoted, although they are of course much more efficient. (Reichenbach, 1939, p. 165, emphases added)

Embracing the continuity of common sense, philosophy, and science is a significant mark of Reichenbach's naturalist thinking. While further stratifications are needed to see more clearly at which points Reichenbach differs from the pragmatists and other American naturalists, Sect. 4 will present a concrete case study of the epistemological and scientific upshots of Reichenbach's scientific philosophy.

\footnotetext{
13 For Reichenbach, the latest scientific achievements brought "a new approach to the significance and possibility of theoretical knowledge in general. With the steep rise in the curve of its development, physics has merged today with a philosophical epoch." And as a consequence, that epoch led to further stratifications in life that also upset people's values, knowledge, morals, and interpersonal behaviors. The precondition for this massive cleaning work (removing old taboos, conventions, habits, and supernatural entities) was a revision "of all conceptual instruments of the production of new intellectual tools, and this may be the reason why querying looks are directed at the work of physicists from so many quarters" (Reichenbach 1930/1978, p. 272).
} 


\section{Liberation of scientific knowledge: from truth to probability}

When Reichenbach introduced and elucidated his scientific epistemology, one of the main topics he discussed in detail was the notion of truth. In this section, we will try to catch his physicalist naturalism in the act by tracing the way in which he tried to clarify the concept of truth and its place in scientific thinking. It is well known that Reichenbach did not take truth to be a significant and legitimate concept in science, and that his scientific epistemology was probability-centered. By replacing truth (the central concept of traditional, academic epistemology) with probability (which is the trademark of his peculiar scientific epistemology), he accomplished what he set out to do: among others, he was able to develop a new kind of fallibilist theory of knowledge; elaborated a peculiar "logistic" empiricist form of verificationism about meaning (in contrast with the positivistic kind of verificationism widely shared by the philosophers of Vienna Circle); offered some more or less convincing reasons why inductive reasoning can be pragmatically justified; and finally, carried out his naturalist program of liberating the human mind and society from the remnants of previous ages. As such, the transition from truth to probability was not simply a definitional enterprise to determine which of these concepts was more fundamental and can and should be used to analyze or explicate the other.

But why was the notion of truth so important for Reichenbach at all? In the introduction to his Axiomatization of the Theory of Relativity, in distinguishing between physics and mathematics, Reichenbach maintains that "[t]o the physicist the question of truth is the most interesting one, for if his theory is true, he can call it in a certain sense a description of reality" (Reichenbach 1924/1969, p. 4). This is why physics is not simply mathematics; mathematical statements are not supposed to describe the world - they are merely consequences of arbitrary definitions: "mathematics is a purely logical science [Denkwissenschaft] [...] [it] is the science of possibility," while "[physics] is the science of actuality," since a physical statement is a description of the world that can only be true if the world cooperates with it in some way (Reichenbach, 1929/1978, p. 134, original emphases). Furthermore, though this view is not uncontroversial, it is widely agreed that scientific inquiries aim at uncovering the truth. It seems that Reichenbach does not contest this, arguing that "we may present as the goal of physics the gaining of true propositions about reality," or more precisely, that "it aims at acquiring the greatest possible number of true assertions" (1929/1978, p. 165, original emphasis). Elsewhere, he notes that "[e]veryone faces the necessity of judging the truth of various assertions, and in daily life, as in science, methods have been developed in accordance with which we more or less consciously make such judgments" (Reichenbach, 1931a/1978, p. 343). As a result, there are two questions that he needed to answer if he wanted to give a full account of truth: "What does it mean for a physical statement to be true?" and "When is a physical statement true?" Importantly, these two questions are not the same.

As is generally accepted, there is a difference between having the property of truth and knowing those propositions or statements which have the property of 
truth. When we try to define the concept of truth, we want to know what it means for a proposition to be true. However, when we try to find which proposition is true, we want to know the criterion according to which we can recognize a true proposition and differentiate it from a false one. Hence, there are at least two tasks about the notion of truth that cannot easily be solved by an empiricist, if at all: on the one hand, the concept of truth should be defined in terms of empirically acceptable concepts, that is, an empiricist could and should grasp the concept of truth as an empirically meaningful one; on the other hand, (s)he has to provide a correct empirical criterion for recognizing truths. The definitional task is not the same as the criterial one, but it is also not clear how these two different questions are related to each other. For most empiricists, these two different tasks are strongly connected. Thus, we can call a theory of truth empirically adequate if it provides not just a definition of truth but also a feasible and, if possible, the best empirical criterion or test of truth. ${ }^{14}$ Let us now take a look at how Reichenbach tried to meet the requirements of a complete empiricist theory of truth.

First of all, he suggests that without taking the actual concept of truth used by scientists/physicists into account, the philosophical debate about the correct definition of truth becomes frivolous:

No doubt we can define the concept of truth in any way we please, but this is not the significance of the problem of truth. The question is, rather, what is the concept that we think of when we speak of truth? Or better: What is the concept of truth that modern science actually employs? This question cannot be answered by means of a definition; the reply will itself constitute substantive information. (Reichenbach, 1929/1978, p. 153)

Reichenbach strongly believes that "the very first condition of empiricism" is nothing less than the correspondence to the practice of science, and that the main task of this practice is to make "assertions about the future," that is, to make predictions (1936, p. 152). As he notes in the paper, "The Physical Concept of Truth," which he presented immediately before Heisenberg's lecture at the Second Conference on the Epistemology of the Exact Sciences in Königsberg in 1930: "it will turn out that the problem of characterizing truth [...] is closely related to the research now being carried out in quantum mechanics" (Reichenbach, 1931a/1978, 344).

Before discussing how Heisenberg's uncertainty principle impacted Reichenbach's epistemology and especially his conception of truth, it is necessary to outline the problems into which Reichenbach ran after some initially promising attempts to define the concept of truth. This is the starting point for our reconstruction of Reichenbach's view about truth: in the early 1920s, he straightforwardly held that Moritz Schlick (1918/1974) offered a convincing account of truth. And in his early

\footnotetext{
14 If the definitional and the criterial questions of truth could be more or less separated, then it would be possible to decide which one is more important. Many truth-theorists think that the basic issue is the nature of truth, and they thus start by trying to give a satisfactory definition of truth. Others think that the definitional project is less interesting, and that the real (and maybe the only) task is to provide an adequate criterion of truth. For a discussion of these issues among the logical empiricists, see Kocsis (2021).
} 
book, The Theory of Relativity and A Priori Knowledge, Reichenbach claims that truth could be perfectly defined in terms of unique coordination:

That theory which continuously leads to consistent coordinations is called true. Schlick is therefore right when he defines truth in terms of unique coordination. We always call a theory true when all chains of reasoning lead to the same number for the same phenomenon. This is the only criterion of truth; it is that criterion which, since the discovery of exact empirical science by Galileo and Newton and of its philosophical justification by Kant, has been regarded as an indispensable test. (Reichenbach, 1920/1965, p. 43, original emphasis)

At this point, Reichenbach was convinced that this special, early Schlickian correspondence theory, in which truth is attributed to a whole, internally consistent scientific theory, provided the best empirically adequate theory of truth, since it offered a definition of truth that can also serve as a useful if not the sole criterion of truth. Based on the empirical concept of truth as unique coordination, any scientific theory would appear to be easily verifiable, since it is possible to check if it produces contradicting results or always "leads to consistent coordinations." As Christopher Pincock (2003, p. 93), emphasizes, "Reichenbach here follows Schlick in placing coordination at the center of his account of scientific knowledge. Reichenbach also agrees with Schlick that univocal or unique coordination is the goal of a scientific theory". ${ }^{15}$

Yet, later on, from the late 1920 s, Reichenbach made explicit his extremely dissatisfaction with the coordinative definition of truth. It should be noted here that Reichenbach, in his arguments against the notion of truth as unique coordination, emphasized that Schlick, by developing a coordinative characterization of truth, made a very important step toward a more sophisticated and tenable "correspondence" theory of truth:

The analysis of the concept of truth by means of the concept of univocal coordination stems principally from Schlick, who recognized the formation of this [coordinative] characterization of truth from the older one through the transformation of naive conception of depiction into the mathematical concept and who supplied its philosophical formulation. (Reichenbach, 1929/1978, p. 154)

For Schlick and Reichenbach, one of the advantages of this recent, coordinative characterization was that it ensured that truth consisted in just such a coordinative relation between the terms of scientific theories as models of reality and the actual elements of reality - which is empirically testable, contrary to the metaphysicallyloaded correspondence theory of truth whose advocates conceded some peculiar and hardly explicable resemblance or agreement relation between the bearers of truth

15 The substance of the early Reichenbach-Schlick exchange (and its broader context) is documented in Oberdan (2009) and Howard (1994). 
(like judgments and statements) or their parts, concepts or signs, and the relevant parts of reality (like facts) or their parts, objects. ${ }^{16}$

However, Reichenbach was discontent even with the new Schlickian formulation, noting that "we cannot yet declare ourselves satisfied with" this characterization of truth (Reichenbach, 1929/1978, p. 154). Accordingly, Reichenbach elucidated some arguments against Schlick's coordination conception of truth, and other versions thereof, such as that put forward by the philosopher-physicist Heinrich Hertz (1899, p. 1) in the introduction to The Principles of Mechanics, though we cannot say if every coordinative definition of truth that Reichenbach presented in his counterarguments and then attacked was ever endorsed by him. ${ }^{17}$

His first and the main problem was that when we elucidate a physical theory about reality, the signs or concepts that we use in a theoretical model and coordinate to real objects cannot be defined so precisely as to provide a complete correspondence between concepts and objects. We can coordinate a concept to an object by a two-step definitional process, which consists, firstly, of a purely conceptual or mathematical definition, that is, a meaning-clarification by means of other concepts, and, secondly, of a physical or real definition, that is, the coordination of the mathematically defined concept to a piece of reality. One of Reichenbach's own examples (see 1920 , p. 37; 1929/1978, pp. 154-155) is the concept of Earth. If, in the first phase, we try to define Earth, say, by virtue of its shape based on the concept of geometrical figures, either that of a spheroid or a rotating ellipsoid, we will get a mathematical definition of the concept of Earth; in the second phase, we can then complete that definition by coordinating our purely conceptually (mathematically) defined concept of Earth to the object Earth itself.

In the discussion of unique coordination, Reichenbach stressed the direction from concepts to objects, which led him to take unique coordination as a criterion for the existence of an object. At the same time, he maintained-contrary to what positivists thought about the reducibility of the notion of existence "to perception and its lawfulness"- that unique coordination cannot provide any definition of existence (Reichenbach, 1929/1978, p. 142). For the positivists, a real object in the external world is a construction from inner perceptual experiences, which for Reichenbach means that they define the concept of existence in terms of perceptibility. Reichenbach always emphasized perceptions, but he never admitted that perceptions could be more than a criterion of what is real. According to Reichenbach, and this is one of the main characteristics of his realism, existence is an indefinable concept; physical objects exist independently of our concepts and theories about them. Reichenbach's realistic commitments require the indispensable role of univocal coordination when attributing truth to a scientific theory:

\footnotetext{
16 As Reichenbach (1929/1978, p. 153) later proclaimed, "[t]he type of coordination that pertains between concept and object is comparable only to mapping in the mathematical sense, not to depicting in the sense of 'creating a similar picture'. Consequently, the concept that we form of an object has no further similarity to it. It is simply coordinated with it, and it is impossible to characterize truth by means of a comparison of the concept with the object".
}

17 We would like to thank one of our anonymous referees for making this point. 
According to Schlick, knowledge consists in the coordination of concepts with objects, and truth demands simply that, going from concept to object, this coordination must be univocal. (The coordination need not be univocal when proceeding in the opposite direction). For our presentation, too, of course, the univocal nature of the coordination is essential; otherwise, it does not make sense, and any objects could be arbitrarily coordinated to the concepts $a_{i}{ }^{*}$. The formulation we offered must, then, be put more precisely, as: 'The objects $a_{i}$, that are univocally coordinated with the concepts $a_{i}{ }^{*}$, exist.' Thus the formulation, 'Truth consists in univocality of coordination', is equivalent to the formulation, 'Truth consists in the existence of univocally coordinated objects.' (Reichenbach, 1929/1978, pp. 153-154)

However, and this is the crux of the realist Reichenbach's problem with defining truth in terms of unique coordination, it cannot be guaranteed that our coordinative definition of a concept constitutes that knowledge of the object to which the concept in question was coordinated. In the abovementioned example about the physical or coordinative definition of the concept of Earth, Reichenbach illustrates that a coordinative definition of Earth cannot be identified with any knowledge of Earth-in other words, the truth of the scientific theory of Earth cannot consist in such a moreor-less precise definition of its shape. Truth, as an absolute notion, requires complete correspondence between the concepts of a scientific model and real objects. While we can define the concept of Earth by means of its coordinative definition, this does not mean that we know exactly what Earth (or its geometric shape) is. According to Reichenbach, this is one of the main problems with the Schlickian unique coordination conception of truth-if we cannot guarantee the complete correspondence between a mathematically defined concept and the real object by means of a coordinative definition, then we have nothing but a more-or-less or approximately correct definition of the concept in question-but this is not true knowledge of an object:

[T] he characterization [of truth] in question pertains solely to the ultimate goal of knowledge and can consequently never be attained. [...] It will not do to reply that we can offer, as a characteristic of the concept earth, the spatial form that the earth really possesses, that we can determine the concept earth by means of the object earth by coordinating the thing to the concept. This process simply gives a definition of the concept earth, in the sense of a coordinating definition [...], it does not amount to knowledge of it. It is only knowledge, not a definition, that possesses the character of truth, and if what we mean by truth is a characteristic coordinating concept and object, the concept cannot be determined by means of this coordination but solely through its connection with other concepts. Hence the univocality of coordination is unattainable precisely where it would constitute knowledge. (Reichenbach, 1929/1978, pp. 154-155, original emphases)

By "knowledge," Reichenbach in this case means a complete scientific theory; as Michael Stöltzner (2013, p. 142) has emphasized, this "led Reichenbach to regard truth so conceived as a property of a coherent system of scientific knowledge". Accordingly, at this point, Reichenbach suggests that we should find another 
conception of truth, which does not appeal to unique coordination at all. Suppose that we have a complete scientific theory: all that is needed is that this theory does not contain any logical contradiction, that is, it should be coherent. However, it is not a solution, as Reichenbach argues, to turn to a coherence theory of truth, because this would cause the fundamental difference between a mathematical and a physical theory to become blurred. As Reichenbach (1924/1969, p. 4) wrote in the introduction to his Axiomatization of the Theory of Relativity, contrary to mathematical statements, "[p]hysical statements are more than mere consequences of arbitrary definitions; they are supposed to describe the real world. This means in the final analysis that phenomena that are directly observable can be derived from them." A logical property such as coherence is just a necessary but not a sufficient condition for determining that a theory as true; a physical theory should be justified by means of the occurrence of the perceptible phenomena that it anticipates. After all, truth cannot consist merely in the coherence of a whole scientific theory:

[I]t must not be forgotten that the logical coherence of the system is not sufficient for the characterization of truth. Perceptions must be included in the system, and the truth of the system demands that no contradictory perceptions occur. Perception is, as it were, the point at which the system is connected to reality: Truth does not only signify freedom from logical contradiction of the system within itself but also agreement at the connecting points. This is just why we can ascribe to this system a meaning for reality over and above its mere logical meaning, just why we can regard it as a description of reality. The concept of truth thus gained also makes a claim regarding a correspondence of the system to reality, even though it only characterizes the system from the inside, so to speak; that the system is true means also that corresponding objects and states of affairs exist. (Reichenbach, 1929/1978, p. 157, original emphases)

The other problem, which is strongly connected to the first one, is that by simply appealing to univocal coordination, we have still not provided a useful criterion of truth, since we cannot step out of the concept formation system to establish whether a mathematically defined concept and the physical object that is coordinated to it correspond completely. Even if, in 1920, Reichenbach believed that unique coordination between concepts and objects provides the sole criterion of truth, by the end of the decade, he doubted the tenability of this truth-criterion, proclaiming that " $\mathrm{t}]$ his characterization does not offer any means whereby the truth of a given physical proposition can be tested" because "the coordination with real objects is exactly what cannot be shown; for purposes of testing scientific propositions, all that we possess are perceptions and theoretical connections" (Reichenbach, 1929/1978, p. $155)$.

This brings us to Reichenbach's third main reason for defying that truth can be an attainable goal of scientific investigations, namely to the problem of the truth of predictive statements. According to Reichenbach (1931a/1978, p. 345), "science never rests content with observation statements, but always goes on to make predictive statements" and if he was right, then we should reject that our best empirically adequate theory of truth is that which defines truth in terms of unique coordination: 
How are we to verify these predictive statements? The experimental physicist's register may be accurate even though the prediction based upon it is false. The truth of predictive statements, then, is different in kind from the truth of observation statements, and herein lies the great epistemological problem of scientific truth. Up to now, philosophers have obscured the problem, transforming predictive statements into observation statements by imagining a later observer who makes his judgment only after the occurrence or non-occurrence of the perceptual experience. But this is a misconstruction of the problem, for it is a decision before confirmation that we require. We need to know how to judge predictive statements as predictions, and transforming predictive statements into observation statements pertaining to a later time does not supply an answer to our problem. (Reichenbach, 1931a/1978, pp. 345-346, original emphasis)

If truth is attainable only by observation, the following dilemma arises: we would then have to introduce two different concepts of scientific truth, one for observational statements and another for predictive statements, or we would have to admit that scientific knowledge contains only observational propositions and that all other apparently scientific propositions should be reduced to mere observational ones. In the latter case, all scientific propositions are observational and seem to be absolutely verifiable. ${ }^{18}$ Reichenbach admits that this could be a solution, but he criticizes it for its total discrepancy with scientific practice.

It is true that this conception leads to a rigorous solution to the problem of truth, but only, alas, at the cost of a gross distortion of physical thinking. The problem of predictive statements has indeed been eliminated, but so has the whole of physics. For physics will never content itself with merely stating past experiences. I can therefore see no solution to the problem in this direction. To deny the meaningfulness of a problem because no satisfactory solution has been found with the conceptual means available to date is not acceptable.

For this reason, I have always regarded the problem of truth as a problem of predictive statements. Certainly, the concept of truth for observation statements is also used in science, for it is ultimately grounded upon epistemological reports, but this concept of truth is not sufficient for science. The truth of predictions is the far more pressing issue. (Reichenbach, 1931a/1978, pp. 346-347)

There would be no theoretical problem with the attainability of truth in a deterministic physics. If our physical world is deterministic, then what will happen in a future moment can be predicted based on the present state of the world. For Reichenbach, it is therefore a crucial question whether the physical world is deterministic or

\footnotetext{
$\overline{18}$ Later on, Schlick (1934/1959) attempted to elucidate such a criterion-providing correspondence theory of truth, but it was only valid for observational statements, that is, his Konstatierungen. However, this is unacceptable for Reichenbach-since restricting scientific statements to observational ones is a fatal error, the main task of a scientific theory is basically to yield more and more accurate predictions.
} 
indeterministic, or more specifically, if there is any evidence to prove that it is (not) deterministic. Why? Because it seems that if we accept that the truth of scientific theories and their statements consists in "a univocal coordination between objects and ideal models" then we will join "the concept of truth to determinism" (Reichenbach, 1931a/1978, p. 344). To illustrate this point, Reichenbach quotes Heinrich Hertz's peculiar formulation of the whole idea of truth as univocal coordination ${ }^{19}$ :

We form for ourselves images or symbols of external objects; and the form which we give them is such that the necessary consequents of the images in thought are always the images of the necessary consequents in nature of the things pictured. (Hertz, 1899, p. 1)

First of all, we need to clarify what the word "deterministic" means. What does it mean for a certain state of the world to determine another state of the world? According to Schlick, for example, determinism means calculability or computability, that is, predictability with certainty ${ }^{20}$ :

The correct interpretation of determinism removes the difficulty at once and leaves to the logical principles their validity. The proposition "the event $\mathrm{E}$ occurs on such and such a day" is timeless-therefore even now either true or false, and only one of the two, quite independently of whether determinism or indeterminism holds in the world. For the latter by no means asserts that today the proposition about the future $\mathrm{E}$ is not unambiguously true or false, but only that the truth or falsity of that proposition cannot be calculated on the basis of propositions about present events. This means, then, that we cannot know whether the proposition is true before the corresponding point in time has passed, but this has nothing to do with its being true or with the basic laws of logic. (Schlick, 1931/1962, p. 292, original emphases)

When we call something indeterministic, we thus assume that we are not able to calculate it, period. However, for Reichenbach, this is not the right conception of indeterminism. The great impact of Heisenberg's indeterminacy or uncertainty principle (which showed that at a given moment we can precisely determine either the position or the momentum of an electron, but not both) on the problem of the tenability of any physicalist account of truth is that (in)determinism cannot be conclusively identified with (in)calculability. But if indeterminism cannot be understood as a pure epistemic notion, then our inability of determining the truth of a predictive statement is not due to our imperfection but to the indeterminacy of reality itself. We therefore agree with Frederick Eberhardt and Clark Glymour's diagnosis of the metaphysical foundations of Reichenbach's new probabilistic conception of scientific truth:

\footnotetext{
19 Again, as we alluded above, though Reichenbach (1920) commended Schlick's coordinative conception of truth, he never admitted, at least not explicitly, to such a Hertzian and deterministic conception of unique coordination. We would like to thank one of our referees for pointing this out.

20 The notion of certainty, especially in the context of probability, played a critical (albeit mainly negative) role in Reichenbach's philosophy. On some of these debates and key ideas for further exploration, see Atkinson and Peijnenburg (2006), and Peijnenbug and Atkinson (2011).
} 
The information we obtain about the external world is not only indirect but also inexact. No empirical procedure supplies perfectly "clean" data. The data is "unclean" for two reasons: First, in measuring a particular parameter, there is always an infinity of other small influences that make the measurement noisy. Second, if Heisenberg's uncertainty principle is not only epistemic, but indicates a true metaphysical uncertainty (and Reichenbach appeared to take this view despite being close friends and an admirer of Einstein), then there is no exact measurement to be had in the first place. (Eberhardt \& Glymour, 2011, pp. 360-361)

The tension in a truth-centered epistemology of science is the following: science gives us the most reliable knowledge about the world, but it is not clear how we can have any knowledge if we are unable to arrive at true propositions. If there is no knowledge without truth, then we are not able to know anything even in science. This yields two options: one is that we adjust scientific thinking to truth-centered epistemology, and the second is to give up on the notion of truth and to try to introduce a new kind of scientific knowledge without a notion as absolute as truth. Reichenbach straightforwardly chose the second option, but this does not mean that he did not provide a new characterization of truth that, according to him, is the only empirically adequate theory of $\operatorname{truth}^{21}$ :

As long as the concept of truth is not grasped from the standpoint of the concept of approximation, it will necessarily remain devoid of content. For we can never experience the ideal itself, but only a process of approximation; thus we can grasp the concept of truth only if the process of approximation has its own independent meaning, only if it defines the concept of truth. The ideal possesses only the significance of a limit, and just as the limit is not something that exists in itself, but simply takes on the meaning possessed by the process of approximation, the scientific concept of truth can only acquire meaning through the formulation of the method of approximation actually used in science. (Reichenbach, 1931a/1978, p. 347)

Here is Reichenbach's final solution to the problem of truth: truth can be defined in terms of probability, but as an unattainable epistemic ideal, truth cannot be useful for empirically based natural sciences. As he puts it,

\footnotetext{
${ }^{21}$ Maybe Reichenbach could have accepted a lightweight, deflationary concept of truth based on the deliberately metaphysically and epistemologically neutral Tarskian (semantic) conception of truth, but he never made any attempt to choose this alternative. Putnam (1994, p. 92) was right in summarizing Reichenbach's position about truth as follows: "Briefly, he rejects the notion of truth as metaphysical. (He never considers a purely disquotational view, as far as I know, but I believe he would have found such a view uninteresting, as not providing us with any substantial notion we can use to appraise the sentences we utter and write for cognitive success.) The notion he proposes in place of the notion of truth, the only notion he has for measuring the cognitive success of an assertion, is the notion of weight, where the weight of a sentence is my estimate of the relative frequency of successful assertions in some appropriate reference class containing the sentence whose weight it is."
} 
There is no truth for physical assertions; probability is all that is attainable. If we nonetheless wish to use the concept of truth, it can play in physics only the role of the limiting case in which the probability is equal to 1 . Truth, then, is the special case of the concept of probability. That is why the concept of truth can only be defined through the concept of probability, and not the reverse. (Reichenbach, 1931a/1978, pp. 354-355)

Thus, Reichenbach elucidated a substantive conception of truth in which truth is an absolute notion, an epistemically ideal limit, whose nature can only be defined in terms of probability. At the same time, according to Reichenbach, we have to admit that we are unable to offer an empirically adequate theory of truth that ensures a useful criterion of truth, that is, we are not able to recognize those propositions that are true in the absolute sense. However, if we cannot ascribe truth values to propositions, meaning we are unable to know precisely which propositions are true, the concept of truth itself, as an unattainable epistemic goal, becomes useless. Consider the following very radical claim of Reichenbach, which is strongly connected to the abovementioned arguments for the unattainability of truth: "To speak of truth or falsehood is legitimate only when there are ways of finding the truth" (quoted in Nilson, 1979, p. 436). According to Reichenbach, truth as a goal of scientific inquiry must be attainable, but is not; and since it is unattainable, it cannot be our epistemic goal. $^{22}$

To sum up, one common thread running through Reichenbach's scientific epistemological arguments against the more-or-less different coordinative characterizations is that attributing truth in science is not legitimate; since we cannot ensure any reliable criterion of truth, we cannot, as a general rule, have a well-functioning concept of truth in the empirical sciences. This is what led him to conclude that "in an epistemologically sophisticated physics," the concept of truth should be replaced with, or at least reduced to, the concept of probability:

This shows nothing other than the necessity of assigning to the concept of probability a position in epistemology superior to the concept of truth. For scientific approximations make use of the concept of probability. The physicist always designates his propositions are more or less probable, but never true. (Reichenbach, 1931a/1978, p. 347)

As such, the concept of truth cannot play a significant role in Reichenbach's scientific epistemology, and his conception of truth as an epistemically unattainable ideal perfectly matched his naturalistic tendencies in treating traditional epistemological questions. As we have seen in the previous section, for Reichenbach, epistemological problems and physical problems are inextricably linked, and we thus

\footnotetext{
22 Latterly, Davidson (2000, p. 67) almost perfectly echoes Reichenbach's conception of truth as an unachievable goal: "[W]hat we will never know for certain is which of the things we believe is true. Since it is neither visible as a target, nor recognizable when achieved, there is no point in calling truth a goal. Truth is not a value, so the 'pursuit of truth' is an empty enterprise unless it means only that it is often worthwhile to increase our confidence in our beliefs, by collecting further evidence or checking our calculations.".
} 
cannot solve any epistemological problem without taking into account the evolution of science, in particular modern physics. For Reichenbach, the only worthwhile task for an epistemologist is liberating natural scientific knowledge from the impractical demands of obsolete academic epistemology; in his words, what we need is "a therapeutic process in which the structure of knowledge is set forth far more clearly than in the earlier, more naive epistemological theory" (Reichenbach, 1931a/1978, p. 354). In a naturalist spirit, Reichenbach thus argues-based on specific findings in physics, in particular Heisenberg's uncertainty principle - that the usage of the concept of truth is incompatible with certain scientific practices, in particular, the process of making appropriate predictions. For us, the way in which Reichenbach attempts to solve the epistemological problems of truth is a perfect example of the liberating, therapeutic form of naturalism to which we referred at the beginning of this essay.

\section{The social function of scientific philosophy}

At one point, Reichenbach (1925/1978, p. 291) even declared that "[w]e must get it clearly in our heads that our knowledge of nature stands or falls with the probability inference". As our knowledge of nature stands or falls on the recognition of possible actions within society, for Reichenbach all goes back to probability with utmost importance. But does probability indeed play such an important role in the broader context, beyond the mere technical admission of the fact? Though Reichenbach's stance on this issue may not be obvious, there are various hints in his writings.

In her recollections on Reichenbach, Cynthia Schuster (back then a young colleague of his at UCLA) recalled a time when she defended Reichenbach's non-cognitivism in ethics by claiming that his philosophy is concerned only "with logic and epistemology, not with social reform." To her amazement, Reichenbach quickly corrected her and stated his own point of view:

But no! That is not true. The whole movement of scientific philosophy is a crusade. It is not clear that only by ending the dogmatism of irresponsible claims to know moral truth, that only by clarity and integrity in epistemology, people can attain tolerance and get along with one another? Don't be misled by the frequency with which others mention their concern for mankind and the infrequency with which I use such words. I dare say I care as much about the future condition of man as anyone you'll ever meet, and what I'm doing aims as directly at social consequences as the programs of those who call themselves 'social reformers'. (Schuster, 1978, pp. 56-57)

This passage is very much in line with the late enlightenment, socio-ethical project of the Viennese logical positivists (Uebel, 2004). In the United States, Reichenbach did not engage personally in socio-political debates as a scientific philosopher. Rather, he thought scientific philosophy could cleanse the public discourse of pseudo-scientific elements, of irresponsible subjective methods not submitted to intersubjective control, of misleading generalizations, and of misuses of actual scientific theories. 
Before we move on, one important issue needs to be highlighted. In his 2017 book, The Philosophy Scare, John McCumber devotes many pages to Hans Reichenbach, especially to The Rise of Scientific Philosophy (1951). McCumber argues that the so-called rational choice theory (RCT) functioned as an economic and political guideline for American policy during the Cold War, as it purports to predict how individuals determine their economic and other preferences (such as voting). For McCumber, the scientific philosophy embedded in Reichenbach's Rise is the philosophical counterpart of RCT, extending RCT's restricted domain of application to the human mind and reason in general and thus giving it an ideological underpinning. In Rise, Reichenbach presents a unified scientific method and reason (a monistic view) that excludes "emotions, history, culture, impositions, and dictatorship" and "thus accords with RCT" on many levels, providing "the kind of philosophy America needed to fight the intellectual Cold War" (McCumber, 2017, p. 102).

It has to be admitted that Rise indeed shows, at first glance, a more monistic view of scientific reason and the human mind than one would expect from a socially engaged philosophy of science. In that sense, Rise could be seen as sharing the letter, perhaps, at certain points, even the spirit, of RCT. Nonetheless, certain reservations apply, and McCumber's account, as important as it may be for the challenges to historians and philosophers of analytic philosophy that it contains, thus has to be supplemented. It is often claimed that non-cognitivism in ethics dethrones morality from its superior position in the human mind and reduces it to some non-truth-apt, emotionally-driven domain. But for many logical empiricists, Reichenbach included, non-cognitivism presented a liberating approach to human life and reasoning; one that is freed from archaic, unchallengeable, socio-politically inherited dogmas. For Reichenbach, the emotional, "tenacious, malleable, indefatigable will" (Reichenbach, 1928/1978, p. 244) within the subject is always present behind numbers, functions, and preferences (cf. Richardson, 2005; Damböck, 2021).

Furthermore, McCumber, besides one small note (2017, p. 96), never considers Reichenbach's overall philosophical and cultural pedigree in detail [for such a discussion of the German cultural background, see the essays in Damböck, Sandner, and Werner (2021)]. Consequently, our paper should be supplemented by a comprehensive historical study of how Reichenbach's thought changed over time and across places. Finally, McCumber is right that Rise is mainly an epistemological work that offers psychological explanations where the issue of the legitimacy of obscure and old philosophies arises. Reichenbach indeed says that an idealist is someone who "resorts to daydreaming because he is unable to enjoy reality in all its moral and aesthetic imperfections" and thus engages in a "philosophical brand of escapism", especially at times of "social catastrophes" (1951, p. 254). But as we will show below, quoting Donata Romizi, in certain times and circumstances, epistemological notions also acquire a socio-political dimension, which is why Reichenbach's epistemological work could, at the very least, be read as evidence of a wider social concern (and this social concern is not necessarily only the domain of the market-oriented Cold War warrior, but also that of the socially inclined enlightener).

As mentioned previously, one way of considering the social dimension within scientific philosophy — or better, the place and role of the social dimension for scientific philosophy—-may be found in Reichenbach's popular work. In the introduction 
to Atom and Cosmos, he justifies his agenda by calling attention to the conceived interests of human beings. He notes that "[t]he urge to knowledge is so deeply rooted in man that it can scarcely be omitted from a list of life's important needs" (Reichenbach, 1932b/1957, p. 18). Nonetheless, Reichenbach does not expect the sciences to deliver any practical knowledge in propositional form; rather, for him, the field of the practical is the realm of "the tenacious, malleable, indefatigable, and yet, eternally modifiable will” (Reichenbach, 1928/1978, p. 244). Or as he put it with a remarkable Kantian overtone, "science gives no answer to such questions as 'What should I do?'” (Reichenbach, 1932b/1957, p. 18).

How then could science, the collection of propositional knowledge, be relevant for citizens besides some obvious technological innovations and implementations? "And yet there is," continues Reichenbach, "a certain psychological connection between science and fundamental human attitudes, between understanding life and assigning values to it. Knowledge as to reality and its laws places us in such a situation that questions about the meaning and value of human doing and being take on a new aspect" (ibid, p. 19). Having an accurate picture of how science works and what its results are would yield certain clues as to how an ethical point of view should be developed-but this is a question for psychology and not for logic.

The psychological question should, of course, be understood quite broadly. Reichenbach's somewhat dated and simplistic, though enlightening, example is the Copernican turn. The actual result and work of Copernicus was of a scientific and technical nature; it concerned the astronomical question whether the Sun moves around the Earth or the other way around. But the whole question also encompassed a moral and a social dimension, as it conveyed the idea of "dethroning the Earth," demoting it from its alleged unique status and role in the universe. This seemingly technical question thus acquired a moral coloring; whether this was right or wrong is immaterial - as humans inevitably strive for knowledge, it is unavoidable that our approaches also take on a moral dimension. As Reichenbach (ibid.) formulates it, "[w]henever science succeeds in combining multitudinous reality in one grand perspective, in which the many single bits of knowledge are united in a picture of the world as a whole, science exerts enormous influence over man's feeling toward life, his fundamental emotional attitude."

That "grand perspective" is of utmost importance; laypeople are not (always) interested in the special technical results and developments of science, but in the "totality of views revealed by science [...], science rounded out to a panorama." But the sciences in general are not interested in this panorama per se; this constitutes an additional task that needs to be done by someone else. Depending on how the picture is drawn, moral life (or at least moral guidance) can be influenced in certain directions. Therefore, it is not at all irrelevant how science is disseminated in a popular form, which lends a definite social value and relevance to Reichenbach's undertakings. ${ }^{23}$

\footnotetext{
23 This ideal of political and social engagement simply by means of pursuing philosophy in a specific context and by specific means is elaborated by Donata Romizi (2012).
} 
Being a naturalist is not a necessary prerequisite for this task; Eddington and Jeans, the famous popularizers of the early twentieth century, were idealists, for example. But being a naturalist means accepting the continuation and harmonization of science, common sense, and philosophy and thus the constant revision of our worldview. As science-which for Reichenbach simply means physics-develops, its cultural projections have to be revealed and discussed as well. The liberation of life from old dogmas and ballasts is thus strongly and inherently connected to the philosophy of science.

In fact, in Atom and Cosmos, Reichenbach explicitly claims that modern science is in a special position "to do without that ballast of traditional conceptions with which historical development has encumbered thought" (1932b/1957, p. 286). This is so because modern science aims only to predict future experiences on the basis of previous ones instead of summarizing and forcing nature into pre-established categories. Viewing science in such a purified and ascetic way, so to speak, may bring with it the charge of 'dehumanizing nature,' given that such an approach allegedly "takes the soul out of physical nature and thus makes it lifeless and uninteresting" (ibid.). In this context, it is useful to recall the early warning in Sect. 2 of Clark (2016, p. 1) who claims that "defined too narrowly, [naturalism] leaves out wide swaths of human thought and experience".

This is indeed a widely shared fear of many critics and defenders of naturalism, which makes it necessary to account for the losses emerging from this process of "naturalization." One option is to simply try to annex more and more of the world by means of the sciences regardless of the intuitive costs (this approach could be attributed, most notoriously, to the Churchlands). Another option would be to fall back on the surface of the matter, claiming that science (and thus philosophy) does not have to deal with any "depths" (Carnap et al. 1929/1973, p. 326). Whatever can be said could be delivered scientifically. Reichenbach thought that the charge of dehumanization came from the worldview of poetry and thus amounted to an inadmissible mixing of the spheres. As he put it, "Such a rejection of the emotional attitude in our acquisition of knowledge of nature does not mean that we would deny the value of the artist's world; it means simply that we decline to bring the artist's concepts into a sphere to which they do not belong" (Reichenbach, 1932b/1957, p. 287).

Why is this important? Because Reichenbach (ibid.) thought that metaphysics is just another form of enlivening nature with supernatural entities such as gods and demons. Substance, time and space, force and law, "all of them [are] of unmistakably anthropomorphic origin" (ibid.) ${ }^{24}$ :

Only the [empirical] experiences, however, and their integration in a prophetic mathematical theory, form the content of modern natural research. Perhaps there has been no greater revolution in the history of mankind than this gradual transition, from the nature, full of gods, of primitive peoples, through the met-

\footnotetext{
${ }^{24}$ Naturalism also tries to place $u s$ in the world, in the complex web of this-worldly affairs. Since many naturalists would refer to their work as demystifying the universe or cleansing the world from its anthropomorphic stains, we could perhaps make a distinction here and say that naturalism aims to achieve all these domestications by introducing humanizing strains into the world.
} 
aphysical nature of the philosophers, to the dispassionate nature of the physics of today, in which there are only facts and conceptual relations between them.

(Reichenbach, 1932b/1957, pp. 287-288)

During the twentieth century, science and philosophy went through many, often quite radical and overwhelming changes, some of which gave rise to new fields and methods. But as science radicalized its own picture of the empirical world, philosophy did not keep pace. Translating the latest results regarding small- and large-scale phenomena into the discourse of philosophers and regular citizens "was perhaps the hardest step of all" - it was the "last step in the liberation of nature from the gods" (Reichenbach, 1932b/1957, p. 288, emphasis added).

The liberation of nature and the inhabitants of the natural world was not just a cognitive or epistemological issue. As Donata Romizi (2012, p. 221) has noted in the context of the Vienna Circle, "some epistemological values can acquire a political meaning in certain historical contexts". Reichenbach's own liberation from the old philosophy and the absolutistic and self-justifying view of common sense in the domains of science and philosophy also emerged in a context in which scientific philosophy gained an immediate social function.

Reichenbach considered the transition from "absolute truth" to probability to be his most important contribution to scientific philosophy: the liberation from truthone of the most hotly pursued and yet ultimately elusive goals of science and philosophy-thus also represented a big step toward a more accountable and democratic stance in living and acting in a new world that is at least as shaped by science as the other way around. Recently, the epistemological reasoning and various cognitive debates about Reichenbach's foundations and technical reconstructions have gained a lot of attention. In this paper, our only aim was to call attention to the wider context of Reichenbach, in order to show him as a compelling but underrated naturalist in the history of analytic philosophy. And, last but not least, to demonstrate, in the midst of the various political turns in analytic philosophy, that even logical empiricists such as Reichenbach-who was often considered a special realist, a developer of quantum logic, or a philosopher of physics with actual physical knowledge-can offer new perspectives and paths to liberation for socially engaged philosophers of science.

Acknowledgements Both authors were supported by the MTA Lendulet Morals and Science Research Group and by the "Empiricism and atomism in the twentieth-century Anglo-Saxon philosophy" NKFI project (124970). László Kocsis was additionally supported by the János Bolyai Research Scholarship of the Hungarian Academy of Sciences (BO/00216/20) and the ÚNKP-20-5 New National Excellence Program of the Ministry for Innovation and Technology from the source of the National Research, Development and Innovation Fund, while Adam Tamas Tuboly was supported by the MTA Premium Postdoctoral Scholarship. We are truly grateful to Jan Faye, Christian Damböck, Charles T. Wolfe, Matthias Neuber and our referees for their valuable comments and suggestions.

Funding Open access funding provided by University of Pécs.

Open Access This article is licensed under a Creative Commons Attribution 4.0 International License, which permits use, sharing, adaptation, distribution and reproduction in any medium or format, as long as you give appropriate credit to the original author(s) and the source, provide a link to the Creative Commons licence, and indicate if changes were made. The images or other third party material in this article 
are included in the article's Creative Commons licence, unless indicated otherwise in a credit line to the material. If material is not included in the article's Creative Commons licence and your intended use is not permitted by statutory regulation or exceeds the permitted use, you will need to obtain permission directly from the copyright holder. To view a copy of this licence, visit http://creativecommons.org/licen ses/by/4.0/.

\section{References}

Atkinson, D., \& Peijnenburg, J. (2006). Probability without certainty: Foundationalism and the LewisReichenbach debate. Studies in History and Philosophy of Science Part A, 37(3), 442-453.

Čapek, M. (1957). The development of Reichenbach's epistemology. The Review of Metaphysics, 11(1), 42-67.

Carnap, R., Hahn, H., \& Neurath, O. (1929/1973). The scientific conception of the world: The Vienna circle. In M. Neurath, \& R. S. Cohen (Eds.), Otto Neurath: Empiricism and sociology (pp. 299318). Dordrecht: D. Reidel.

Clark, K. J. (2016). Naturalism and discontents. In K. J. Clark (Ed.), The Blackwell companion to naturalism (pp. 1-15). Wiley Blackwell.

Damböck, C. (2021). Carnap, Reichenbach, Freyer. Non-cognitivist ethics and politics in the spirit of the German Youth-Movement. In C. Damböck, G. Sandner, \& M. Werner (Eds.), Logical empiricism, life reform, and the German youth movement/Logischer empirismus, Lebensreform und die deutsche Jugendbewegung. Dordrecht: Springer.

Davidson, D. (2000). Truth rehabilitated. In R. B. Brandom (Ed.), Rorty and his critics (pp. 65-74). Blackwell.

Dewey, J. (1910). The influence of Darwin on philosophy. In J. Dewey (Ed.), The influence of Darwin on philosophy and other essays (pp. 1-19). Henry Holt and Company.

Donata, R. (2012). The vienna circle's "scientific world-conception": Philosophy of science in the political arena. HOPOS: The Journal of the International Society for the History of Philosophy of Science, 2(2), 205-242. https://doi.org/10.1086/666659.

Dretske, F. (1995). Naturalizing the mind. MIT Press.

Eberhardt, F., \& Glymour, C. (2011). Hans Reichenbach's probabilistic logic. In D. M. Gabbay, J. Woods, \& S. Hartmann (Eds.), Handbook of the history of logic (vol. 10, pp. 357-389).

Eddington, A. (1928). The nature of the physical world. Cambridge University Press.

Fischer, E., \& Collins, J. (2015). Ratonalism and naturalism in the age of experimental philosophy. In E. Fischer \& J. Collins (Eds.), Experimental philosophy, rationalism, and naturalism: Rethinking philosophical method (pp. 3-33). Routledge.

Frank, P. (1941/1949). Why do scientists and philosophers so often disagree about the merits of a new theory?. In Modern science and its philosophy (pp. 207-215). Cambridge, Mass.: Harvard University Press.

Hertz, H. (1899). The principles of mechanics: Presented in a new form. Macmillan and Co.

Hook, S. (1930). A Personal impression of contemporary German philosophy. The Journal of Philosophy, 27(6), 141-160.

Howard, D. (1994). Einstein, Kant, and the origins of logical empiricism. In W. Salmon, \& G. Wolters (Eds.), Logic, language, and the structure of theories: Proceedings of the Carnap-Reichenbach Centennial, University of Konstanz, 21-24 May 1991 (pp. 45-105). Pittsburgh-Konstanz: University of Pittsburgh Press-Universitätsverlag Konstanz.

Howard, D. (2006). Lost wanderers in the forest of knowledge: Some thoughts on the discovery-justification distinction. In J. Schickore \& F. Steinle (Eds.), Revisiting discovery and justification: historical and philosophical perspectives on the context distinction (pp. 3-22). Springer.

Jewett, A. (2011). Canonizing Dewey: Naturalism, logical empiricism, and the idea of american philosophy. Modern Intellectual History, 8(1), 91-125.

Kamlah, A. (2013). Everybody has the right to do what he wants: Hans Reichenbach's volitionism and its historical roots. In N. Milkov \& V. Peckhaus (Eds.), The Berlin group and the philosophy of logical empiricism (pp. 151-175). Springer. 
Kocsis, L. (2021). Definition versus criterion: Ayer on the problem of truth and validation. In A. T. Tuboly (Ed.), The historical and philosophical significance of Ayer's language, truth and logic (pp. 279-303). Basingstoke: Palgrave.

McCumber, J. (2017). The philosophy scare: The politics of reason in the early cold war. University of Chicago Press.

McMahon, W. E. (1976). Hans Reichenbach's philosophy of grammar. Mouton.

Nagel, E. (1938). Review of Hans Reichenbach's Experience and prediction. The Journal of Philosophy, 35(10), 270-272.

Nagel, E. (1947/1954). Philosophy and the American temper. In Sovereign reason and other studies in the philosophy of science (pp. 50-57). Glencoe, Illinois: The Free Press.

Neuber, M., \& Tuboly, A. T. (Eds.). (2021). Ernest Nagel: Philosophy of science and the fight for clarity. Springer.

Nilson, D. R. (1979). Hans Reichenbach on the logic of quantum mechanics. In W. C. Salmon (Ed.), Hans Reichenbach: logical empiricists (pp. 427-474). D. Reidel.

Oberdan, T. (2009). Geometry, convention, and the relativized a priori. In F. Stadler, H. J. Wendel, \& E. Glassner (Eds.), Stationen: Dem philosophen und physiker moritz schlick zum (vol. 125, pp. 186211). Geburtstag. Wien,New York: Springer.

Padovani, F. (2011). Relativizing the relativized a priori: Reichenbach's axioms of coordination divided. Synthese, 181(1), 41-62.

Padovani, F. (2021). From physical possibility to probability and back: Reichenbach's account of coordination. In S. Lutz, \& A. T. Tuboly (Eds.), Logical empiricism and the physical sciences: From philosophy of nature to philosophy of physics (pp. 336-353). New York: Routledge.

Peijnenburg, J., \& Atkinson, D. (2011). Grounds and limits: Reichenbach and foundationalist epistemology. Synthese, 181(1), 113-124.

Pincock, C. (2003). Carnap and the unity of science: 1921-1928. In T. Bonk (Ed.), Language, truth and knowledge: contributions to the philosophy of rudolf carnap (pp. 88-96). Dordrecht: Kluwer.

Psillos, S. (2011). On Reichenbach's argument for scientific realism. Synthese, 181(1), 23-40.

Putnam, H. (1994). Words and life. Edited by James Conant. Cambridge, MA: Harvard University Press.

Putnam, H. (2001). Hans Reichenbach: Realist and verificationist. In J. Floyd \& S. Shieh (Eds.), Future pasts (pp. 277-288). Oxford University Press.

Randall, J. H. (1944). Epilogue: The nature of naturalism. In Y. Krikorian (Ed.), Naturalism and the human spirit (pp. 354-384). Columbia University Press.

Reichenbach, H. (1920/1965). Theory of relativity and a priori knowledge. Berkeley-Los Angeles: University of California Press.

Reichenbach, H. (1924/1969). Axiomatization of the theory of relativity. Berkeley-Los Angeles: University of California Press.

Reichenbach, H. (1925/1978). Metaphysics and natural science. In M. Reichenbach, \& R. S. Cohen (Ed.), Selected writings 1909-1953 (vol. 1, pp. 283-297). Dordrecht: D. Reidel.

Reichenbach, H. (1928/1978). The world view of the exact sciences. In M. Reichenbach, \& R. S. Cohen (Ed.), Selected writings 1909-1953 (vol. 1, pp. 241-244). Dordrecht: D. Reidel.

Reichenbach, H. (1929/1978). The aims and methods of physical knowledge. In M. Reichenbach, \& R. S. Cohen (Ed.), Selected writings 1909-1953 (vol. 2, pp. 120-225). Dordrecht: D. Reidel.

Reichenbach, H. (1930/1978). The Present State of the Sciences: The Exact Natural Sciences. In M. Reichenbach, \& R. S. Cohen (Ed.), Selected writings 1909-1953 (vol. 1, pp. 270-272). Dordrecht: D. Reidel.

Reichenbach, H. (1931a/1978). The physical concept of truth. In M. Reichenbach, \& R. S. Cohen (Ed.), Selected writings 1909-1953 (vol. 1, pp. 343-355). Dordrecht: D. Reidel.

Reichenbach, H. (1931b/1978). Aims and methods of modern philosophy of nature. In M. Reichenbach, \& R. S. Cohen (Ed.), Selected writings 1909-1953 (vol. 1, pp. 359-388). Dordrecht: D. Reidel.

Reichenbach, H. (1932a/1978). Is the human mind capable of change? An interview. In M. Reichenbach, \& R. S. Cohen (Ed.), Selected writings 1909-1953 (vol. 1, pp. 275-279). Dordrecht: D. Reidel.

Reichenbach, H. (1932b/1957). Atom and Cosmos: The World of Modern Physics. New York: George Braziller, Inc.

Reichenbach, H. (1936). Logistic empiricism in Germany and the present state of its problems. The Journal of Philosophy, 33(6), 141-160.

Reichenbach, H. (1938). Experience and prediction. University of Chicago Press.

Reichenbach, H. (1939). Dewey's theory of science. In P. A. Schilpp (Ed.), The philosophy of John Dewey. New York: Tudor Publishing Company. 
Reichenbach, H. (1951). The rise of scientific philosophy. University of California Press.

Reisch, G. (2005). How the cold war transformed philosophy of science: To the Icy slopes of logic. Cambridge University Press.

Richardson, A. (2000). Science as will and representation: Carnap, Reichenbach, and the sociology of science. Philosophy of Science, 67, 312-321.

Richardson, A. (2005). The tenacious, malleable, indefatigable, and yet, eternally modifiable will': Hans Reichenbach's knowing subject. Aristotelian Society Supplementary, 79(1), 73-87.

Richardson, A. (2006). Freedom in a scientific society: Reading the context of Reichenbach's contexts. In J. Schickore \& F. Steinle (Eds.), Revisiting discovery and justification: Historical and philosophical perspectives on the context distinction (pp. 41-54). Springer.

Schlick, M. (1918/1974). General theory of knowledge (A. E. Blumberg,Trand.). New York and Wien: Springer.

Schlick, M. (1931/1962). Causality in contemporary physics (II). The British Journal for the Philosophy of Science, 12(48), 281-298.

Schlick, M. (1934/1959). On the foundation of knowledge. In A. J. Ayer (Ed.), Logical positivism (pp. 209-227). New York: The Free Press.

Schuster, C. (1978). U.C.L.A., 1945-1950: Cynthia Schuster. In H. Reichenbach, \& R. S. Cohen (Ed.), Selected writings 1909-1953 (vol. 1, pp. 55-58). Dordrecht: D. Reidel.

Stöltzner, M. (2013). Did Reichenbach anticipate quantum mechanical indeterminism? In N. Milkov \& V. Peckhaus (Eds.), The Berlin group and the philosophy of logical empiricism (pp. 123-150). Springer.

Tuboly, A. T. (2021). Understanding metaphysics and understanding through metaphysics: Philipp Frank on scientific theories and their domestication. In S. Lutz \& A. T. Tuboly (Eds.), Logical empiricism and the physical sciences: From philosophy of nature to philosophy of physics (pp. 401-421). Routledge.

Uebel, T. (2004). Education, enlightenment and positivism: The Vienna circle's scientific world-conception revisited. Science \& Education, 13, 41-66.

Uebel, T. (2007). Empiricism at the crossroads: The Vienna circle's protocol-sentence debate. Open Court.

Verhaegh, S. (2018). Working from within: the nature and development of Quine's naturalism. Oxford University Press.

Verhaegh, S. (2020). Coming to America: Carnap, Reichenbach and the great intellectual migration. Part II: Hans Reichenbach. Journal for the History of Analytical Philosophy, 8(11). https://jhaponline. org/jhap/article/view/4562.

Wagner, P. (Ed.). (2012). Carnap's Ideal of explication and naturalism. Palgrave Macmillan.

Publisher's Note Springer Nature remains neutral with regard to jurisdictional claims in published maps and institutional affiliations.

\section{Authors and Affiliations}

\section{László Kocsis ${ }^{1}$ (D) Adam Tamas Tuboly ${ }^{2,3}$ id}

László Kocsis

kocsis.laszlo@gmail.com

Adam Tamas Tuboly

tubolyadamtamas@gmail.com

1 Department of Philosophy, University of Pécs, Pécs, Hungary

2 Institute of Philosophy, Research Center for the Humanities, ELRN, Budapest, Hungary

3 Institute of Transdisciplinary Discoveries, Medical School, University of Pécs, Pécs, Hungary 